\title{
Stability analysis of grid-connected converters with add-on voltage support functionality using repetitive control
}

\section{Citation for published version (APA):}

Zhang, Y., Roes, M. G. L., Hendrix, M. A. M., \& Duarte, J. L. (2018). Stability analysis of grid-connected converters with add-on voltage support functionality using repetitive control. In 2018 International Power Electronics Conference, IPEC-Niigata - ECCE Asia 2018 (pp. 946-952). [8507757] Institute of Electrical and Electronics Engineers. https://doi.org/10.23919/IPEC.2018.8507757

DOI:

10.23919/IPEC.2018.8507757

Document status and date:

Published: 22/10/2018

\section{Document Version:}

Accepted manuscript including changes made at the peer-review stage

\section{Please check the document version of this publication:}

- A submitted manuscript is the version of the article upon submission and before peer-review. There can be important differences between the submitted version and the official published version of record. People interested in the research are advised to contact the author for the final version of the publication, or visit the $\mathrm{DOI}$ to the publisher's website.

- The final author version and the galley proof are versions of the publication after peer review.

- The final published version features the final layout of the paper including the volume, issue and page numbers.

Link to publication

\section{General rights}

Copyright and moral rights for the publications made accessible in the public portal are retained by the authors and/or other copyright owners and it is a condition of accessing publications that users recognise and abide by the legal requirements associated with these rights.

- Users may download and print one copy of any publication from the public portal for the purpose of private study or research.

- You may not further distribute the material or use it for any profit-making activity or commercial gain

- You may freely distribute the URL identifying the publication in the public portal.

If the publication is distributed under the terms of Article 25fa of the Dutch Copyright Act, indicated by the "Taverne" license above, please follow below link for the End User Agreement:

www.tue.nl/taverne

Take down policy

If you believe that this document breaches copyright please contact us at:

openaccess@tue.nl

providing details and we will investigate your claim. 


\title{
Stability Analysis of Grid-connected Converters with Add-on Voltage Support Functionality using Repetitive Control
}

\author{
Y. Zhang*, M. G. L. Roes, M. A. M. Hendrix and J. L. Duarte \\ Department of Electrical Engineering \\ Eindhoven University of Technology \\ P.O. Box 513, 5600MB Eindhoven, The Netherlands \\ *E-mail: ya.zhang@tue.nl
}

\begin{abstract}
The aim of this paper is to analyse the stability of grid-connected converters using repetitive control for voltage harmonic compensation. Supplementary to an earlier proposed control strategy to upgrade grid-connected converters for add-on voltage support, the stability analysis of the overall system is presented. A straightforward procedure is proposed and a couple of stability conditions are derived. The analysis is broken down into two subparts and therefore, the Nyquist's criterion can be easily applied. Simulations and experiments support the stability model analysis. The proposed method is not limited to the application with voltage support but also applicable for other converter systems based on repetitive-control algorithms.
\end{abstract}

Keywords-grid-connected converter, repetitive-control, stability, voltage support

\section{INTRODUCTION}

Power electronic converters are widely applied to interface sustainable energy sources with the public grid and local loads [1]-[4]. Figure 1 shows the typical diagram of a single-phase grid-connected converter with local loads. In such a converter the local voltage is conventionally measured for grid synchronization and the converter output current is measured for active power regulation [5]-[9]. This type of converter generally experiences difficulties to compensate (the local grid voltage) for harmonic distortions that are generated by the local load currents, unless an additional sensor of the non-linear load current [10]-[13], or the grid current [14], or the grid voltage [15] is applied. In the application where multiple non-linear loads are connected to the point of common connection (PCC), more than one additional sensor would become necessary, which adds up to the total cost of the converter system.

As demonstrated in [16], [17], a single-phase gridconnected inverter can be incorporated with an added functionality to sink the non-linear load current harmonics without using an additional sensor. This is achieved by employing a dedicated control strategy, where the PCC voltage is used for more than grid synchronization, e.g. for harmonic compensation to improve the local voltage quality. This is advantageous for the local grid, especially for a grid where the non-linear loads are the main contributor to the harmonics. Since the harmonics are locally countered, the distortion of the current to the grid can be diminished as a consequence.

Compared to regular current controllers applied in grid-connected converters [5], [18]-[20], the control strategy in [17] exhibits distinctive features, e.g. two references and two control loops in parallel, which makes a single-input single-output (SISO) feedback control strategy not applicable. In addition to that, since both proportional-resonance (PR) and repetitive-control (RC) algorithms were applied, the stability analysis of the overall system is non-trivial. A straightforward procedure is proposed and a couple of stability conditions are derived in this paper. The proposed stability analysis strategy is also applicable for a SISO converter system using repetitive-control, since a SISO system can be considered as an extreme case of a single-input dual-output servo.

The structure of the paper is as follows. Firstly, the voltage support control strategy for a single-phase grid-connected converter system is recalled. Then the procedure to derive the stability conditions of the overall system is presented. In Section IV considerations of the control design are discussed. This is followed by simulation results in Section V and experimental results in Section VI. Finally, conclusions are drawn in Section VII.

\section{RECALL OF THE CONTROL STRATEGY WITH ADD-ON VOLTAGE SUPPORT FUNCTIONALITY}

Figure 2 shows the structure of the control strategy. The control strategy for additional voltage harmonic compensation includes two loops [16], one for active power regulation and another for harmonic compensation. The $\mathrm{RC}$ algorithm is applied in the second loop. There the discrete-Fourier-transformation (DFT) filter is applied to selectively compensate for harmonics. The transfer function of the DFT filter in the z-domain is

$$
C_{D F T}(z)=\frac{2}{N} \sum_{i=0}^{N-1}\left(\sum_{h \in N_{h}} \cos \left[\frac{2 \pi}{N} h i\right]\right) z^{-i}
$$

where $N_{h}$ and $N$ are the set of harmonics to be compensated and the number of samples per grid period, respectively. The transfer function of the proportional- 


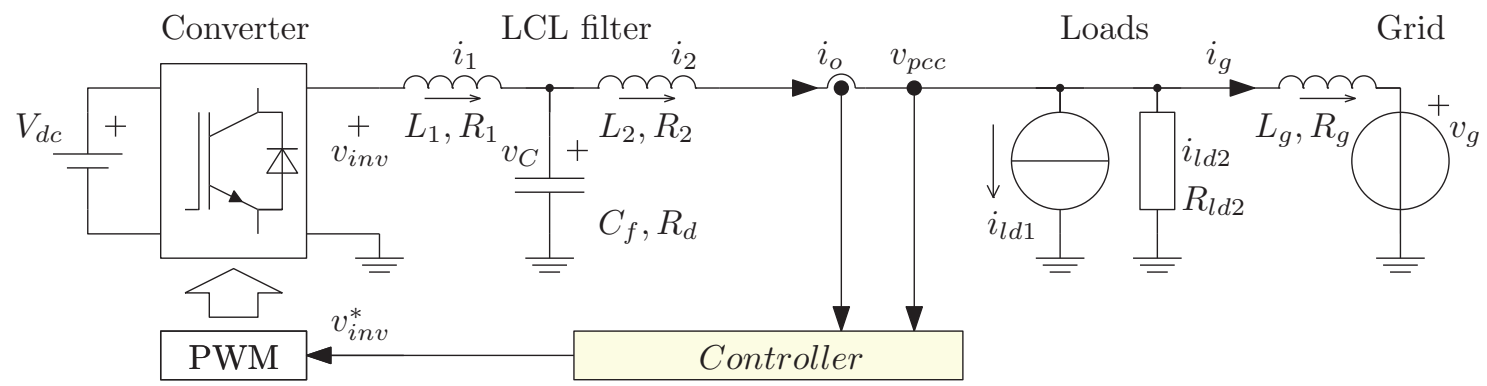

Fig. 1. System diagram of a single-phase grid-connected inverter with LCL filter and local loads

resonance filter in the s-domain is

$$
G_{p r}(s)=K_{p}+K_{r} \frac{s}{s^{2}+\omega_{o}^{2}},
$$

where $K_{p}$ is the proportional gain, $K_{r}$ the resonance gain, and $\omega_{0}$ the central resonance frequency which is designed to be equal to the grid angular frequency.

\section{SYSTEM MODELLING AND STABILITY CONDITION DERIVATION}

This section presents a procedure to derive a closedloop dynamic model of the grid-connected inverter of Fig. 1 with the controller of Fig. 2. Subsequently, based on the derived model a couple of stability conditions are formulated.

\section{A. Modelling of the inverter and delay of PWM}

The open-loop transfer function from the desired inverter output voltage $v_{i n v}^{*}$ to the inverter's output voltage $v_{\text {inv }}$ (refer to Fig. 1) is denoted as $H_{0}(s)$. Taking into account the calculation time and the delays caused by pulse-width-modulation (PWM), we approximate $H_{0}(s)$ as

$$
H_{0}(s)=e^{-s T_{s}},
$$

where $T_{s}$ is the sampling period. The sampling frequency $f_{s}=\frac{1}{T_{s}}$ is identical to the inverter's switching frequency.

\section{B. LCL filter and grid}

The current source $i_{l d 1}$ in Fig. 1 denotes the nonlinear load and the voltage source $v_{g}$ represents the grid. Both $i_{l d 1}$ and $v_{g}$ are regarded as external disturbances and therefore the former is regarded as an open-circuit and another as a short-circuit during small-signal modelling. Therefore, the open loop dynamics from the inverter output voltage to the converter output current and the PCC voltage can be described by a 4 th order state-space model, written as

$$
\begin{aligned}
\frac{\mathrm{d}}{\mathrm{d} t} x(t) & =A_{c} x(t)+B_{c} u(t) \\
y(t) & =C_{c} x(t),
\end{aligned}
$$

where the input, states and outputs correspond to

$$
u(t)=v_{i n v}(t), x(t)=\left[\begin{array}{c}
i_{1}(t) \\
i_{2}(t) \\
i_{g}(t) \\
v_{C}(t)
\end{array}\right], y(t)=\left[\begin{array}{c}
i_{o}(t) \\
v_{p c c}(t)
\end{array}\right]
$$

The matrices in (4) are found to be

$A_{c}=$

$\left[\begin{array}{cccc}-\frac{R_{1}+R_{d}}{L_{1}} & \frac{R_{d}}{L_{1}} & 0 & -\frac{1}{L_{1}} \\ \frac{R_{d}}{L_{2}} & -\frac{R_{d}+R_{l d 2}+R_{2}}{L_{2}} & \frac{R_{l d 2}}{L_{2}} & \frac{1}{L_{2}} \\ 0 & \frac{R_{l d 2}}{L_{g}} & -\frac{R_{d}+R_{l d 2}}{L_{g}} & 0 \\ \frac{1}{C_{f}} & -\frac{1}{C_{f}} & 0 & 0\end{array}\right]$
$B_{c}=\left[\begin{array}{llll}\frac{1}{L_{1}} & 0 & 0 & 0\end{array}\right]^{T}, C_{c}=\left[\begin{array}{cccc}0 & 1 & 0 & 0 \\ 0 & R_{l d 2} & -R_{l d 2} & 0\end{array}\right]$.

The transfer functions from the input to the outputs can be obtained as follows:

$$
\left[\begin{array}{l}
H_{1}(s) \\
H_{2}(s)
\end{array}\right]=C_{c}\left(s I-A_{c}\right)^{-1} B_{c} .
$$

We can see that $H_{1}(s)$ and $H_{2}(s)$ are the transfer functions from $v_{i n v}(s)$ to $i_{o}(s)$ and to $v_{p c c}(s)$, respectively. The zero-order-hold method is used for the discretization of $H_{0}(s), H_{1}(s)$ and $H_{2}(s)$, which results in $H_{0}(z)$, $H_{1}(s)$ and $H_{2}(z)$, respectively.

\section{Closed-loop model}

Figure 3 shows the closed loop diagram where the plant is given by Fig. 1 and the controller by Fig. 2 . The two references $r_{1}$ and $r_{2}$ in Fig. 3 correspond to the desired fundamental inverter output current $i_{o, 1}^{*}$ and the desired pcc voltage harmonic content $v_{p c c, h}^{*}$ (zero under normal circumstances) in Fig. 2; the two outputs $y_{1}$ and $y_{2}$ correspond to the inverter output current $i_{o}$ and the pcc voltage $v_{p c c}$ in Fig. 1, respectively. The system in Fig. 3 is a single-input dual-output feedback control system, and 


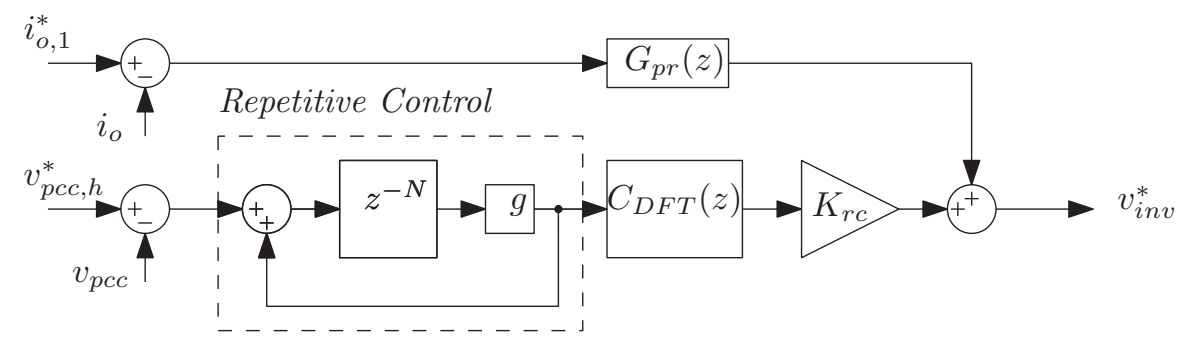

Fig. 2. Structure of the control strategy using repetitive-control for add-on voltage harmonic compensation

we have

Controller: $\quad c_{1}(z)=G_{p r}(z)$

$$
\begin{aligned}
c_{2}(z) & =\frac{g z^{-N}}{1-g z^{-N}} C_{D F T}(z) K_{r c} \\
\text { Plant: } \quad p_{1}(z) & =H_{0}(z) H_{1}(z) \\
p_{2}(z) & =H_{0}(z) H_{2}(z)
\end{aligned}
$$

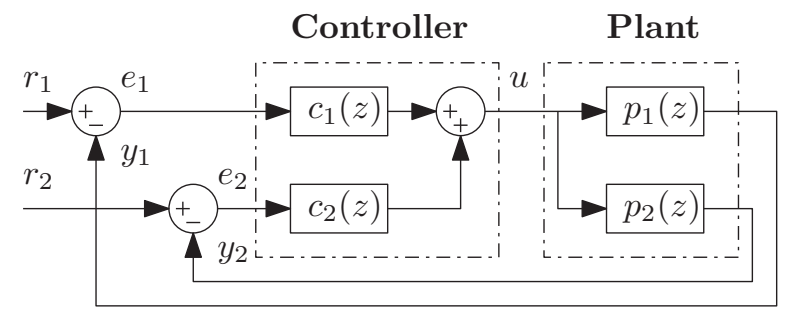

Fig. 3. Diagram of a single input dual output feedback control system.

Analysing the closed-loop system model in Fig. 3 yields a transfer function matrix, given by

$$
\left[\begin{array}{l}
y_{1}(z) \\
y_{2}(z)
\end{array}\right]=\left[\begin{array}{cc}
\frac{p_{1}(z) c_{1}(z)}{1+T(z)} & \frac{p_{1}(z) c_{2}(z)}{1+T(z)} \\
\frac{p_{2}(z) c_{1}(z)}{1+T(z)} & \frac{p_{2}(z) c_{2}(z)}{1+T(z)}
\end{array}\right]\left[\begin{array}{l}
r_{1}(z) \\
r_{2}(z)
\end{array}\right],
$$

where $T(z)$ is

$$
T(z)=p_{1}(z) c_{1}(z)+p_{2}(z) c_{2}(z) .
$$

It can be seen from (10) that all the entries in the closed-loop transfer function matrix share the same denominator, and that $T(z)$ is the loop gain transfer function of the system. Therefore, $T(z)$ can be analysed to derive the stability conditions of the system in Fig. 3.

\section{Stability condition derivation}

The closed-loop characteristic polynomial of the system in Fig. 3 is

$$
D(z)=1+T(z)
$$

From substituting (8) into (11) and (12) follows

$$
D(z)=1+p_{1}(z) c_{1}(z)+\frac{p_{2}(z) g z^{-N} C_{D F T}(z) K_{r c}}{1-g z^{-N}} .
$$

Observing (13) indicates that the closed-loop characteristic polynomial $D(z)$ is of quite high order, making a direct application of Nyquist's Stability Criterion not straightforward. By decomposition of $D(z)$, however, it is possible to reach a set of stability conditions. Denoting

$$
\begin{aligned}
& \bar{T}_{1}(z)=p_{1}(z) c_{1}(z) \\
& \bar{T}_{2}(z)=-g z^{-N}\left(1-\mathcal{P}(z) C_{D F T}(z) K_{r c}(z)\right) \\
& \mathcal{P}(z)=\frac{p_{2}(z)}{1+p_{1}(z) c_{1}(z)}
\end{aligned}
$$

the polynomial in (13) is rewritten as

$$
D(z)=\frac{\left(1+\bar{T}_{1}(z)\right)\left(1+\bar{T}_{2}(z)\right)}{1-g z^{-N}} .
$$

Since $\bar{T}_{1}(z)$ is stable and $g$ is chosen smaller than one, a set of sufficient stability conditions of the system in Fig. 3 is therefore derived as follows:

Condition 1 The equation $1+\bar{T}_{1}(z)=0$ has no unstable roots;

Condition 2 The equation $1+\bar{T}_{2}(z)=0$ has no unstable roots.

As a result, with the proposed analysis procedure in this section, the overall system stability problem is broken down into two explicit sub-problems.

\section{CONTROL DESIGN CONSIDERATIONS}

This section discusses how to properly tune the control parameters to satisfy the stability conditions derived in Section III-D. Table I lists the parameters of the gridconnected converter that are used for the examples in this section (with reference to Fig. 1). The controller parameters are set according to Table II unless mentioned otherwise.

It can be observed from the expressions of $\bar{T}_{1}(z)$ and $\bar{T}_{2}(z)$ that weather condition $\mathbf{1}$ holds is determined by $c_{1}(z)$ alone; for condition $\mathbf{2}$ this is determined by both $c_{1}(z)$ and $c_{2}(z)$. Therefore, the stability strategy is to satisfy condition $\mathbf{1}$ first and thereafter satisfy condition 2.

\section{A. Transfer function $\bar{T}_{1}(z)$}

Using the control parameters in Table II, the Nyquist plot of $\bar{T}_{1}(z)$ is depicted in Fig. 4. It can be concluded that the sufficient stability condition $\mathbf{1}$ in Section III-D 
TABLE I. GRID-CONNECTED CONVERTER PARAMETERS

\begin{tabular}{lcc}
\hline Description & Symbol & Value \\
\hline DC power supply voltage & $V_{d c}$ & $400 \mathrm{~V}$ \\
Converter switching frequency & $f_{s w}$ & $10 \mathrm{kHz}$ \\
LCL filter & $L_{1}, R_{1}$ & $5.22 \mathrm{mH}, 0.2 \Omega$ \\
& $C_{f}, R_{d}$ & $2.82 \mu \mathrm{F}, 0.2 \Omega$ \\
& $L_{2}, R_{2}$ & $5.22 \mathrm{mH}, 0.2 \Omega$ \\
Linear load resistance & $R_{l d 2}$ & $94 \Omega$ \\
Grid rms voltage & $V_{g}$ & $220 \mathrm{~V}$ \\
Nominal grid frequency & $f_{g}$ & $50 \mathrm{~Hz}$ \\
Grid impedance & $L_{g}$ & $10.44 \mathrm{mH}$ \\
& $R_{g}$ & $0.4 \Omega$ \\
\hline
\end{tabular}

TABLE II. INITIAL CONTROL PARAMETERS

\begin{tabular}{lcc}
\hline Parameters & Symbol & Value \\
\hline Sampling rate & $f_{s}$ & $10 \mathrm{kHz}$ \\
PR filter & $K_{p}$ & 30 \\
& $K_{r}$ & 6000 \\
& $\omega_{0}$ & $2 \pi f_{g}$ \\
RC filter & $N$ & 200 \\
& $N_{h}$ & $\{3,5,7\}$ \\
& $K_{r c}$ & 1.2 \\
& $g$ & 0.99 \\
\hline
\end{tabular}

is satisfied. Moreover, it can be observed from the expression of $c_{1}(z)$ in (8) and (2) that decreasing $K_{p}$ and $K_{r}$ simultaneously will make condition 1 easier to be satisfied.

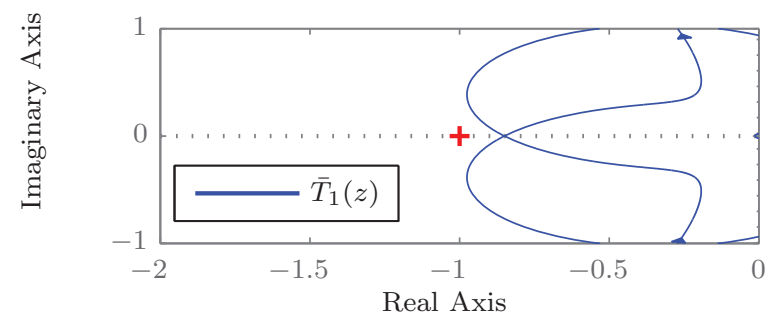

Fig. 4. Nyquist plot of $\bar{T}_{1}(z)$.

\section{B. Transfer function $\bar{T}_{2}(z)$}

Using the control parameters in Table II, the Nyquist plot of $\bar{T}_{2}(z)$ is depicted in Fig. 5 with two different values of $g$. It can be concluded that the sufficient stability condition 2 in Section III-D is satisfied in both cases. Clearly, decreasing $g$ helps to increase the system gain margin, according to the expression of $\bar{T}_{2}$ in $(15)$ and its Nyquist plot in Fig. 5.

\section{Simulation Results}

A series of simulations were performed in Matlab/Simulink/Plecs to investigate the stability discussion in Section IV. An H-bridge is chosen for the converter indicated in Fig. 1. Since a weak grid, namely a grid with relatively large grid impedance, experiences more difficulties in maintaining the local voltage quality in the presence of local non-linear loads, a weak grid

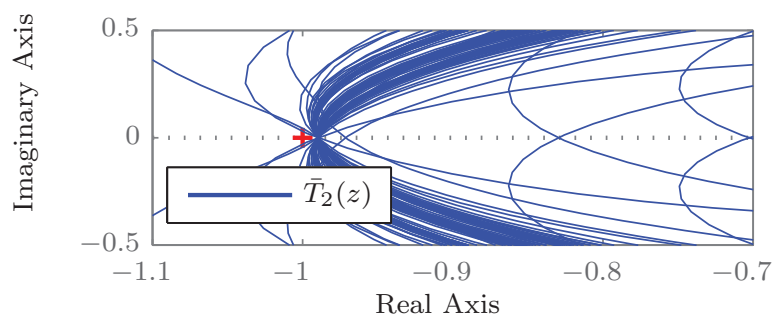

(a)

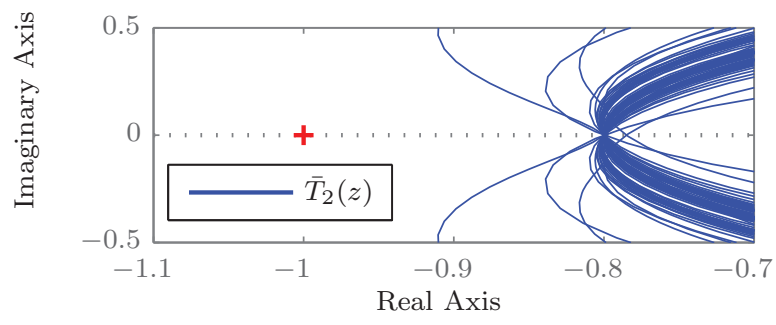

(b)

Fig. 5. Nyquist plot of $\bar{T}_{2}(z)$ : (a) with $g=0.99$; (b) with $g=0.8$.

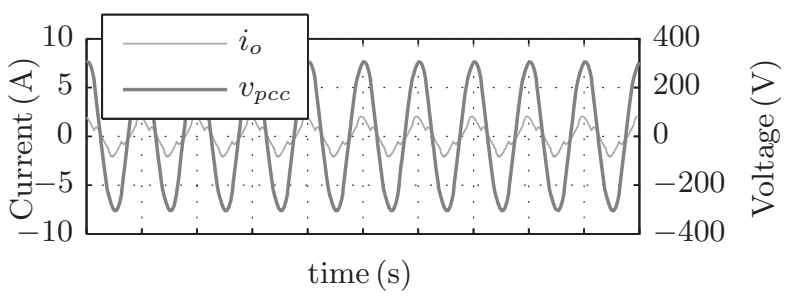

Fig. 6. Simulation results. The RC loop in Fig. 2 disabled resulting in high PCC voltage distortion $\left(\operatorname{THD}\left(v_{p c c}\right)=3.82 \%\right)$.

is assumed in this paper. The parameters of the gridconnected converter system is shown in Table I. In the simulation the sampling process is synchronized with respect to the converter switching behaviour according to the considerations in [21], and therefore, the sampling rate coincides with the switching frequency.

Figure 6 and Figure 7 show the simulation results when the RC loop is disabled $\left(c_{2}=0\right)$ and enabled. It can be observed that compared to when the RC loop is disabled in Fig. 6, the PCC voltage waveform is less distorted when the RC loop is enabled in Fig. 7. A further analysis indicates that the total harmonic distortion (THD) of the PCC voltage is $3.82 \%$ in Fig. 6 and $1.07 \%$ in Fig. 7 , which numerically validates the improvement in the PCC

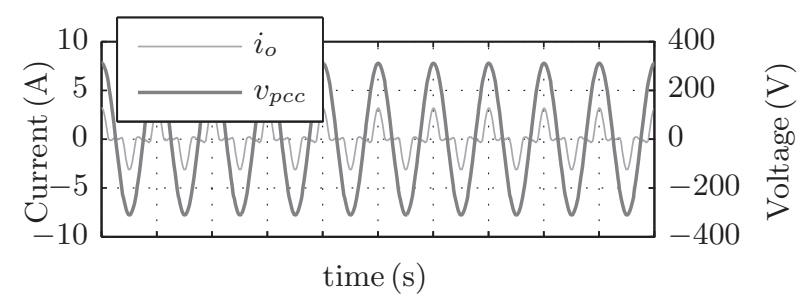

Fig. 7. Simulation results. The RC loop in Fig. 2 enabled resulting in low PCC voltage distortion, $g=0.99$ $\left(\operatorname{THD}\left(v_{p c c}\right)=1.07 \%\right)$. 


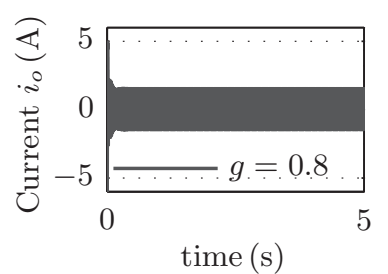

(a)

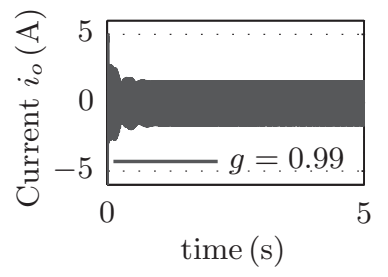

(c)

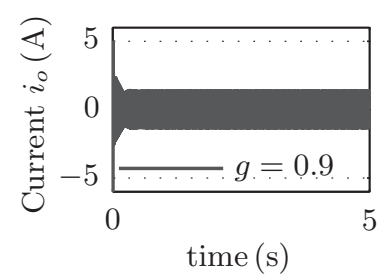

(b)

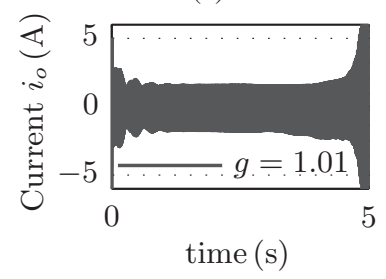

(d)
Fig. 8. Simulated waveform of $i_{o}$ with different values of $g$.

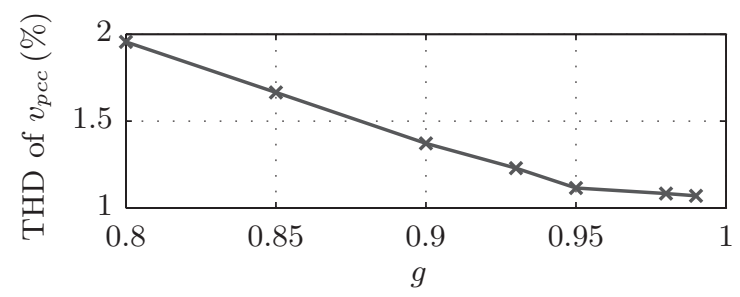

Fig. 9. Simulation results. Total harmonic distortion of the pcc voltage with different values of $g$.

voltage quality.

Figure 8 shows the start-up transient dynamics of the converter with different values of $g$. It can be seen that decreasing $g$ accelerates the stabilization of the system; however, consequently, the PCC voltage THD increases, as shown in Fig. 9. In a deliberately even worse case (in Fig. 8(d)) the system becomes unstable when $g$ is bigger than one, which is in agreement with the stability discussions in Section IV, Fig. 5.

\section{EXPERIMENTAL RESULTS}

This section considers the overall system performance in experiments, including steady-state and transient behaviours. A laboratory setup was realised in accordance with the system diagram shown in Fig. 1. It consists of: a DC power supply, a single-phase H-bridge converter, an LCL filter, a linear load, a programmable load, a Spitzenberger type DM 3000 grid emulator and a $d S P A C E$ DS1 104 real-time control system. The nominal parameters of the converter system are shown in Table I; the control parameters are set according to Table II.

\section{A. Steady-state performance}

When the pulse-width-modulation of the inverter is disabled, Figure 10 and Figure 11 show the respective experimental results when the non-linear load is disconnected from and connected to the PCC. Figure 12 and Figure 13 show the respective experimental results when the RC loop is disabled and enabled. Comparing Fig.

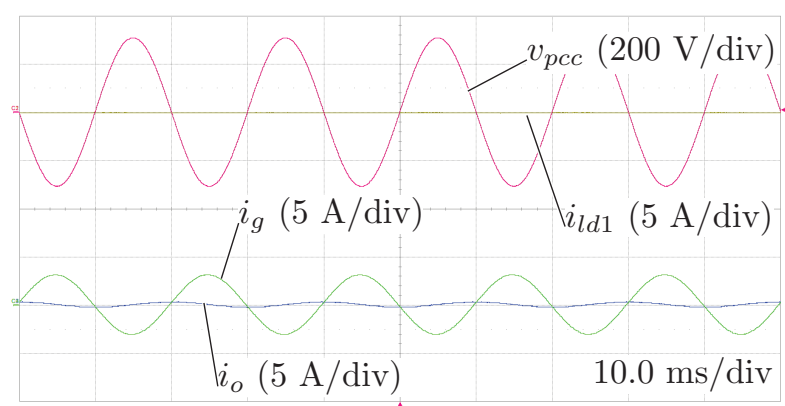

Fig. 10. Experimental results. The non-linear load is disconnected, resulting in low PCC voltage distortion.

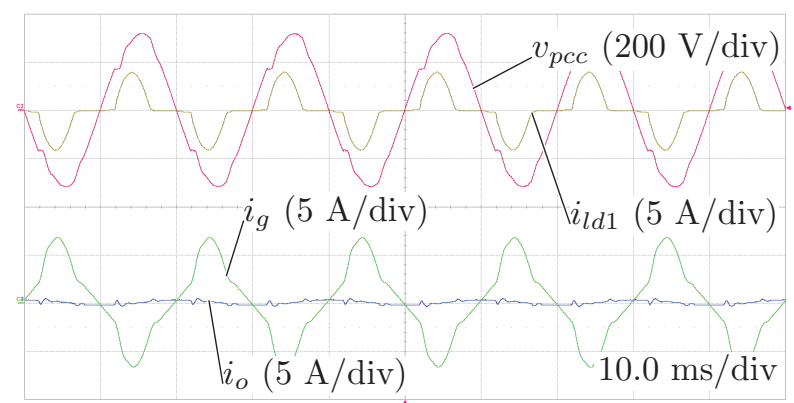

Fig. 11. Experimental results. The non-linear load is connected, resulting in high PCC voltage distortion $\left(\operatorname{THD}\left(v_{p c c}\right)=6.65 \%\right)$.

10 and Fig. 11 indicates that the non-linear load can distort the local PCC voltage. However, using only the conventional PR current controller, the harmonics are poorly suppressed, as demonstrated in Fig. 12. When the $\mathrm{RC}$ loop is enabled, the local PCC voltage distortion is reduced, as shown in Fig. 13, which is in accordance with the simulation results in Section $\mathrm{V}$.

Figure 14 shows the results when $g$ is set to 0.8 . It can be seen that the grid current in Fig. 14 is more distorted than in the situation in Fig. 13. The experimental THD of the PCC voltage against $g$ is plotted in Fig. 15. It can be seen that increasing $g$ results in lower THD of the local PCC voltage, which is in agreement with the simulation results in Section V. Nevertheless, it is noticeable that the experiments (Fig. 15) show more total harmonic distortion than the simulation (Fig. 9), which could be explained by two main factors. Firstly, the non-linear load in simulation

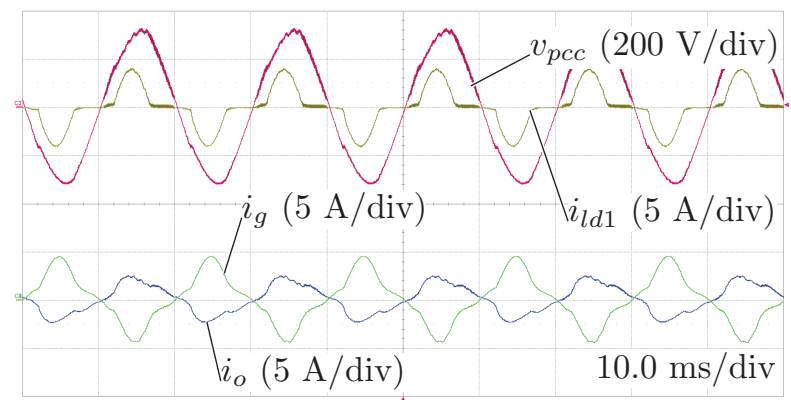

Fig. 12. Experimental results. The RC loop in Fig. 2 disabled resulting in high PCC voltage distortion $\left(\operatorname{THD}\left(v_{p c c}\right)=4.45 \%\right)$. 


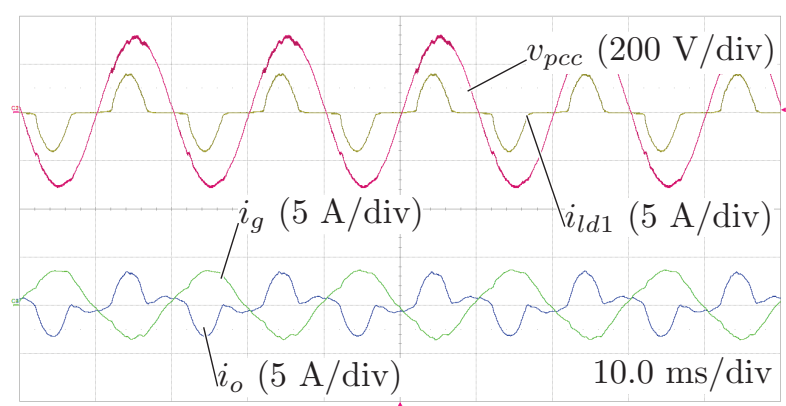

Fig. 13. Experimental results. The RC loop in Fig. 2 enabled resulting in reduced PCC voltage distortion, $g=0.99$ $\left(\operatorname{THD}\left(v_{p c c}\right)=2.28 \%\right)$.

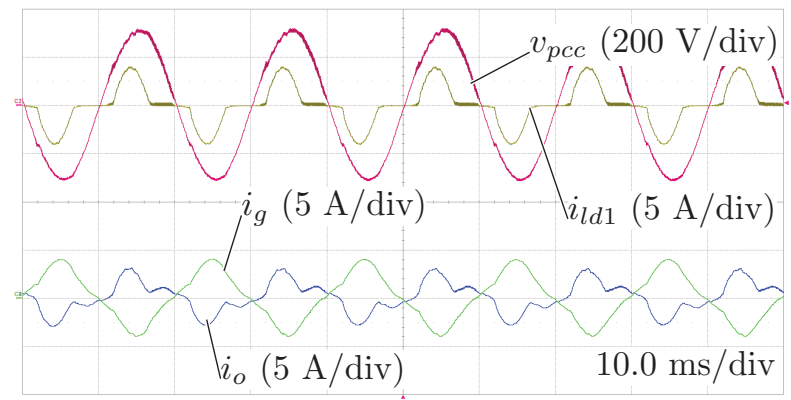

Fig. 14. Experimental results. The RC loop in Fig. 2 enabled and $g=0.80$.

is not exactly the same as in experiments. The former one is created by two Zener diodes anti-series-connected. In experiments the non-linear load is programmed to have a root mean square value of $2 \mathrm{~A}$, a Crest factor of 2 and a power factor of 0.8 . Secondly, the performance of the repetitive-control algorithm is highly dependent on the grid frequency estimation accuracy. In simulation the grid frequency is perfectly stabilized at a set value; however, in practice the grid frequency was between $49.93 \mathrm{~Hz}$ and $49.97 \mathrm{~Hz}$.

\section{B. Transient performance}

The experimental transient dynamics of the converter when changing the value of $g$ are shown in Fig. 16 . Consistent to the prediction from the model analysis and the observation in simulation, the system keeps stable when $g$ is changed from 1 to 0.99 and unstable when

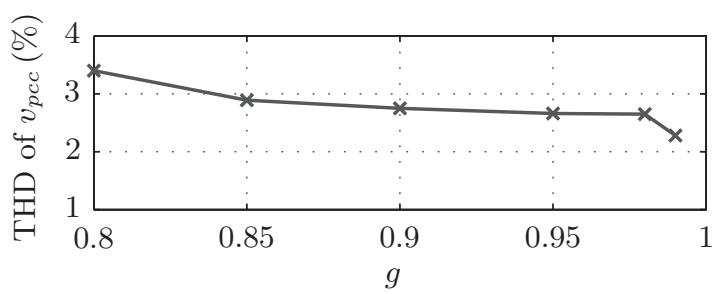

Fig. 15. Experimental results. Total harmonic distortion of the pcc voltage with different values of $g$. $g$ is changed from 1 to 1.01 .

As mentioned earlier, a smaller $g$ increases the overall system stability gain margins at the cost of reduced harmonic attenuation. In the extreme case, $g=0$, the voltage support functionality is disabled (with reference to the control strategy structure in Fig. 2); in this case the stability condition $\mathbf{2}$ in Section III-D is always satisfied.

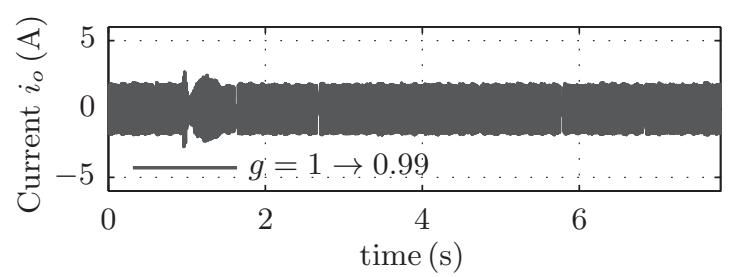

(a)

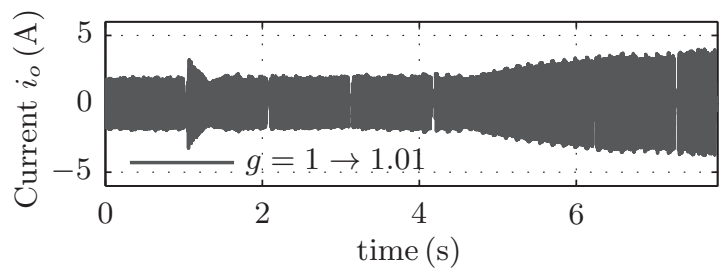

(b)

Fig. 16. Experimental results. Waveform of $i_{o}$ when changing $g=1$ to (a) 0.99 at around $1 \mathrm{~s}$; (b) 1.01 at around $1 \mathrm{~s}$.

\section{CONCLUSION}

As an extension of the proposed control strategy of grid-connected converters with add-on voltage support in [17], this paper presents the stability analysis. It introduces a method to quantify the stability margins of the proposed strategy thus improving the robustness of the system.

Theoretically, when the feedback gain in the RC is unity, zero-error disturbance rejection is achievable; however, it is at the cost of bringing the system operating at boundary stability condition. A gain smaller than one results in a system that stabilizes faster. However, the disturbance rejection ability is less; namely, reduced performance in voltage harmonic attenuation. As demonstrated by simulation and experimental results in this paper, there is a trade-off between stability margins and the performance of harmonic disturbance rejection.

\section{ACKNOWLEDGEMENT}

This project has received funding from the Electronic Components and Systems for European Leadership Joint Undertaking under grant agreement No 737434. This Joint Undertaking receives support from the European Unions Horizon 2020 research and innovation programme and Germany, Slovakia, Netherlands, Spain, Italy. 


\section{REFERENCES}

[1] Y. Yang, K. Zhou, H. Wang, F. Blaabjerg, D. Wang, and B. Zhang, "Frequency adaptive selective harmonic control for grid-connected inverters," IEEE Transactions on Power Electronics, vol. 30, no. 7, pp. 3912-3924, Jul. 2015.

[2] Y. Yang, K. Zhou, and F. Blaabjerg, "Enhancing the frequency adaptability of periodic current controllers with a fixed sampling rate for grid-connected power converters," IEEE Transactions on Power Electronics, vol. 31, no. 10, pp. 7273-7285, Oct. 2016.

[3] M. Castilla, J. Miret, J. Matas, L. G. d. Vicuna, and J. M. Guerrero, "Linear current control scheme with series resonant harmonic compensator for single-phase grid-connected photovoltaic inverters," IEEE Transactions on Industrial Electronics, vol. 55, no. 7, pp. 2724-2733, Jul. 2008.

[4] P. M. d. Almeida, J. L. Duarte, P. F. Ribeiro, and P. G. Barbosa, "Repetitive controller for improving grid-connected photovoltaic systems," IET Power Electronics, vol. 7, no. 6, pp. 1466-1474, Jun. 2014.

[5] M. Castilla, J. Miret, J. Matas, L. G. d. Vicuna, and J. M. Guerrero, "Control design guidelines for single-phase grid-connected photovoltaic inverters with damped resonant harmonic compensators," IEEE Transactions on Industrial Electronics, vol. 56, no. 11, pp. 4492-4501, Nov. 2009.

[6] J. Xu, Q. Qian, S. Xie, and B. Zhang, "Grid-voltage feedforward based control for grid-connected LCL-filtered inverter with high robustness and low grid current distortion in weak grid," in IEEE Applied Power Electronics Conference and Exposition (APEC), Mar. 2016, pp. 1919-1925.

[7] S. H. Lee, W. J. Cha, B. H. Kwon, and M. Kim, "Discrete-time repetitive control of flyback CCM inverter for PV power applications," IEEE Transactions on Industrial Electronics, vol. 63, no. 2, pp. 976-984, Feb. 2016.

[8] X. Li, J. Fang, Y. Tang, X. Wu, and Y. Geng, "Capacitorvoltage feedforward with full delay compensation to improve weak grids adaptability of LCL-filtered grid-connected converters for distributed generation systems," IEEE Transactions on Power Electronics, vol. 33, no. 1, pp. 749-764, Jan. 2018.

[9] Q. Zhao, Y. Ye, G. Xu, and M. Zhu, "Improved repetitive control scheme for grid-connected inverter with frequency adaptation," IET Power Electronics, vol. 9, no. 5, pp. 883-890, Apr. 2016.

[10] R. I. Bojoi, L. R. Limongi, D. Roiu, and A. Tenconi, "Enhanced power quality control strategy for single-phase inverters in distributed generation systems," IEEE Transactions on Power Electronics, vol. 26, no. 3, pp. 798-806, Mar. 2011.

[11] M. Rashed, C. Klumpner, and G. Asher, "Repetitive and resonant control for a single-phase grid-connected hybrid cascaded multilevel converter," IEEE Transactions on Power Electronics, vol. 28, no. 5, pp. 2224-2234, May 2013.

[12] Z. Yao and L. Xiao, "Control of single-phase grid-connected inverters with nonlinear loads," IEEE Transactions on Industrial Electronics, vol. 60, no. 4, pp. 1384-1389, Apr. 2013.

[13] R. R. Chilipi, N. A. Sayari, A. R. Beig, and K. A. Hosani, "A multitasking control algorithm for grid-connected inverters in distributed generation applications using adaptive noise cancellation filters," IEEE Transactions on Energy Conversion, vol. 31, no. 2, pp. 714-727, Jun. 2016.

[14] J. Miret, M. Castilla, J. Matas, J. M. Guerrero, and J. C. Vasquez, "Selective harmonic-compensation control for single-phase active power filter with high harmonic rejection," IEEE Transactions on Industrial Electronics, vol. 56, no. 8, pp. 3117-3127, Aug. 2009.

[15] R. A. Mastromauro, M. Liserre, T. Kerekes, and A. Dell'Aquila, "A single-phase grid-connected photovoltaic systems with power quality conditioner functionality," IEEE Transactions on Industrial Electronics, vol. 56, no. 11, pp. 4436-4444, Nov. 2009.

[16] Y. Zhang, M. A. M. Hendrix, M. G. L. Roes, J. L. Duarte, and E. A. Lomonova, "Voltage harmonics suppression add-on functionality without additional sensors for existing grid-connected inverters," in 19th European Conference on Power Electronics and Applications (EPE'17 ECCE Europe), Sep. 2017, pp. 1-10.
[17] Y. Zhang, M. A. M. Hendrix, M. G. L. Roes, and J. L. Duarte, "Grid-connected converters with voltage support using only local measurements," in IEEE 8th International Symposium on Power Electronics for Distributed Generation Systems (PEDG), Apr 2017, pp. 1-6.

[18] M. Liserre, R. Teodorescu, and F. Blaabjerg, "Stability of photovoltaic and wind turbine grid-connected inverters for a large set of grid impedance values," IEEE Transactions on Power Electronics, vol. 21, no. 1, pp. 263-272, Jan. 2006.

[19] Y. Yang, K. Zhou, and F. Blaabjerg, "Current harmonics from single-phase grid-connected inverters - examination and suppression," IEEE Journal of Emerging and Selected Topics in Power Electronics, vol. 4, no. 1, pp. 221-233, Mar. 2016.

[20] S. Golestan, E. Ebrahimzadeh, J. M. Guerrero, and J. C. Vasquez, "An adaptive resonant regulator for single-phase grid-tied VSCs," IEEE Transactions on Power Electronics, vol. 33, no. 3, pp. 1867 1873, Mar. 2018.

[21] L. Corradini, D. Maksimovic, P. Mattavelli, and R. Zane, The Digital Control Loop. Wiley-IEEE Press, 2015, pp. 51-78. 